\title{
PASE ATRÁS Y ADELANTE Y RECEPCIÓN
}

\section{Jon Macareno Ramos}

Universidad del País Vasco / Euskal Herriko Unibertsitatea. Dpto. Escultura y de Arte y Tecnología Grupo de Investigación GIC IT1096/16-21

\section{Resumen}

Esta investigación explora aquellos instantes en donde el parque y los equipamientos para el ocio y la práctica deportiva en la ciudad dan origen a expresiones y prácticas que superan la función previa que les determina. A lo largo del texto se estudia un caso particular acontecido en el frontón del barrio de Rekalde (Bilbao), que ilustra la complejidad de los procesos de urbanización y sus repercusiones sociales, a menudo acometida desde una concepción del arte como legitimador. Palabras clave: ARTE URBANO; ESPACIO URBANO; JUEGO; DEPORTE;
PARQUE; CULTURA; REKALDE (BILBAO)

\section{PASS BACK AND AHEAD AND RECEPTION}

\section{Abstract}

This research explores those moments where the park and the equipment for leisure and sports in the city give rise to expressions and practices that go beyond the previous function that determines them. Throughout the text, a particular case that occurred in the fronton of the RekaIde neighborhood (Bilbao), is studied, illustrating the complexity of urban processes and their social repercussions, often undertaken from a conception of art as legitimating.

Keywords: URBAN ART; URBAN SPACE; PLAY; SPORT; PARK; CULTURE; REKALDE (BILBAO)

\footnotetext{
Macareno Ramos, Jon. 2020. “Pase atrás y adelante y recepción “. AusArt 8 (2): 179-192. DOI: 10.1387/ausart.22100
}

\section{AUSART}


No había nada como el baloncesto estival en el parque, especialmente jugar a baloncesto en Buttonwood Park.

El parque tenía dos buenas canchas al aire libre, y estaba ubicado aproximadamente en el centro de New Bedford, por lo que la mayoría de los jugadores podían llegar allí. Estaba muy cerca del West End, hogar de muchas familias afroamericanas, y lo suficientemente cerca de South-Central y South End, donde vivían la población caboverdiana y latina.

Como resultado, era la zona de recreo donde tenían lugar los mejores partidos y en donde, además, la raza era irrelevante.

Así, todas las noches alrededor de las seis los mejores jugadores empezaban a llegar. Chicos que ya se habían graduado en la escuela secundaria y ahora jugaban en la universidad. Chicos fuera de la universidad que seguían perseverando. Niños de secundaria, como yo, que intentaban hacerse un nombre. E incluso muchachos de muy lejos, que tan solo querían participar del mejor juego, las mejores competiciones y jugar con los mejores muchachos de la zona.

Jugábamos como si fuera a vida o muerte, hasta que oscurecía demasiado. Partido tras partido, los ganadores se quedaban en la cancha, con docenas de jugadores esperando, tratando de entrar en juego.

(Kavanaugh 2017¹)

\section{LA ARQUITECTURA Y EL CUERPO. ESPACIO LÚDICO-ESPACIO TALLER}

Una plataforma arquitectónica construida bajo la demanda de una especialidad deportiva concreta, en este caso el baloncesto, se configura a través de un diseño estandarizado que se define en la disposición de las rayas multicolores que delimitan las reglas del juego y el posicionamiento de los cuerpos en su práctica, las canastas a la altura reglamentaria y los aros confeccionados en base al diámetro de la pelota. Dicho dispositivo urbano cumple su función original como receptor y congregador de talento, deseos y prácticas culturales. 
Todo espacio levantado para el desarrollo de los ejercicios que determina una disciplina deportiva, es un espacio activo.

La insistencia en la ejercitación para la práctica de la técnica del baloncesto está dirigida, en su objetivo más pragmático y materialista, a encestar la pelota y lograr canastas de 1 (tiro libre), 2 (cuando éstas se ejecutan dentro del espacio delimitado por la línea de triple) o 3 puntos (triple, canasta efectuada más allá de la línea de triple). Para ello, deben ponerse en marcha innumerables rutinas relacionadas con el cuerpo y su interacción interpersonal y con el espacio, la percepción, la potencia, etc. desplegadas en la técnica de tiro, el reverso, el rebote, la posición de defensa, el pase, el bloqueo o la entrada a canasta, entre otras muchas. La práctica continuada de un mismo movimiento hasta lograr interiorizarlo en el repertorio corporal supone encontrar solución a un problema/obstáculo planteado en el evento deportivo. Todas estas herramientas de las que dispone la propia idiosincrasia del baloncesto se ponen al servicio de la experimentación a través de la acción lúdica. Es en estas rutinas o prácticas donde se sitúan los objetivos que tienen que ver con el impulso lúdico y su correspondiente desdén hacia la inercia de un mundo exigente y frustrante.

La práctica del skateboarding es igualmente un claro ejemplo de insistencia en la repetición y ensayo de sus movimientos (llamados trucos si atendemos a su diccionario técnico) hasta lograr dominarlos ya que son éstos los que fundamentan el ejercicio de esta disciplina. La perseverancia en la ejecución exacta de un truco prepara y dispone al patinador para la experiencia del patinaje y la expresión individual y creativa a través del mismo. La senda del juego enmarcada en el skateboarding fluye a través de múltiples combinaciones, variantes, excesos, transformaciones y cadencias que el patinador despliega en un acto creador.

Entendemos que el objetivo del juego es el juego mismo, el abandono a una dinámica en donde la relación con el mundo es más intensa y se muestra libre de la normativa que guía el discurrir de nuestro pensamiento cotidiano. De igual manera, podríamos trazar una similitud con la práctica del arte, donde la ejercitación en base a las diferentes y múltiples operaciones dadas en relación al material, tienen como objetivo hallar soluciones formales, levantamientos materiales que responden a la técnica que le es propia al arte. ${ }^{2}$ Así, el uso de un taladro al que se le ha introducido una broca del número 8 para realizar un agujero en un listón de metal y posteriormente meter un tornillo para sujetarlo a otro listón más ancho de metal, con la idea de que esta suma alumbre 
una forma estética, entra dentro de la rutina de la práctica escultórica. Podría entenderse esa operación taladro-agujero-tornillo-fijación como un reverso ejecutado con la pretensión de encarar la canasta para encestar 2 puntos y conseguir la victoria o como un ollie ${ }^{3}$ que permite al patinador adentrarse en la pista de skate.

Su autonomía (la del juego) se ve asediada por prohibiciones y consejos que obedecen a la preocupación: lo lúdico siempre está delimitado, porque jugar fuera de sitio es irreverente y peligroso, $y$ el juego ya está fuera de sitio, dividido contra sí mismo.

(Larsen 2014, 19)

\section{CUANDO EL JUEGO SE DESBORDA. TUS MUERTOS}

El juego enmarcado en los límites de una especialidad deportiva se expande más allá del uso de los botes intencionados de un balón o de la conformación de equipos dispuestos para competir y dar expresión ritual al evento de una batalla. Los espacios urbanos habilitados para el disfrute del ocio a menudo se ven desbordados en su función original y dan lugar y cobijo a prácticas que responden a una cultura en torno a la especificad de dicha práctica deportiva. Las paredes de hormigón desnudo soportan y precipitan la forja de una identidad de grupo que encuentra canal de expresión en la materialidad espacial del parque. De esta manera, al término de los partidos entre equipos o en los descansos de los mismos, la experimentación lúdica no se detiene y reafirma el interés por desbordar la frontera entre el espacio normativo y aquel que promueve rupturas con un orden consensuado. A menudo jugar un partido tres contra tres, patinar en el skatepark o hacer una tanda de penaltis no se presentan desnudos o aislados de posiciones ideológicas y vitales, formando parte de una cultura adolescente y juvenil que pone en marcha toda una serie de hitos personales que refuerzan el desarrollo psicosocial de los individuos.

Nuestra época contemporánea entiende el parque como espacio lúdico, siendo la economía del ocio uno de los parámetros sobre los que se cimienta en la actualidad el desarrollo urbano y la ciudad, en donde se regula el relajamiento de las normas cívicas: se permite florecer a la naturaleza, soltar a las 
mascotas, quitarse la camiseta, pisar el césped, permanecer tumbado, chutar el balón, sobrepasar el límite de decibelios, etc.

A principios del siglo $\mathrm{XX}$ el concepto de juego y su naturaleza experimental formó parte del programa moderno, reconociéndolo como una herramienta imprescindible dentro del repertorio de las funciones propias del ser humano que consolidan su desarrollo evolutivo. Arquitectos, urbanistas, escultores y paisajistas llegaron al consenso de que, para la consecución de una sociedad emancipada, la experiencia lúdica debería jugar un papel fundamental en la ordenación del territorio y la ciudad, facilitando al ciudadano espacios donde fortalecer su conciencia/compromiso individual y comunitario. A este respecto, se discutiría la conveniencia o no de situar dichos espacios recreativos integrados en la ciudad o en localizaciones interiores resguardadas de la calle.

Esta cuestión, la inserción arquitectónica de la posibilidad para el juego dentro o fuera de las ciudades, es determinante para la configuración del paisaje urbano y su impacto social. A este respecto, el escultor Jorge Oteiza (19082003), en base a su ideario estrechamente ligado a la modernidad, refiriéndose al frontón, construcción característica que encarna una de las expresiones deportivas más populares del País Vasco como es la pelota, afirma que:

Al quedar vacío (reeducada nuestra sensibilidad) debiera funcionar para nuestra intimidad religiosa tradicional como un aislador metafísico. Este tipo de construcciones-cromlech en el interior de las grandes ciudades congestionadas de expresión, son zonas-gris (estéticamente), de aparcamiento de la sensibilidad formada. Como los 'Jardines de piedras de Kyoto'.

(Oteiza, [1963], 2009, 59)

El frontón, equipamiento deportivo en forma de caja rectangular abierta, una especie de hangar destinado al juego dentro del tumulto exaltado por edificios y carreteras, posee gran relevancia en la cultura e identidad vasca. Todas las ciudades, sus barrios y los pueblos integran en su fisionomía el frontón, dando servicio comunitario más allá del propio juego de pelota, siendo a su vez lugar para el encuentro y la celebración grupal en forma de eventos socioculturales $y$, muy a menudo también como veremos más adelante, zona para el refugio. Se trata pues de una construcción altamente compleja en lo simbólico que, más allá de su función destinada a la pelota, incorpora entre sus muros francos múltiples expresiones profundamente vitales y espontáneas. 


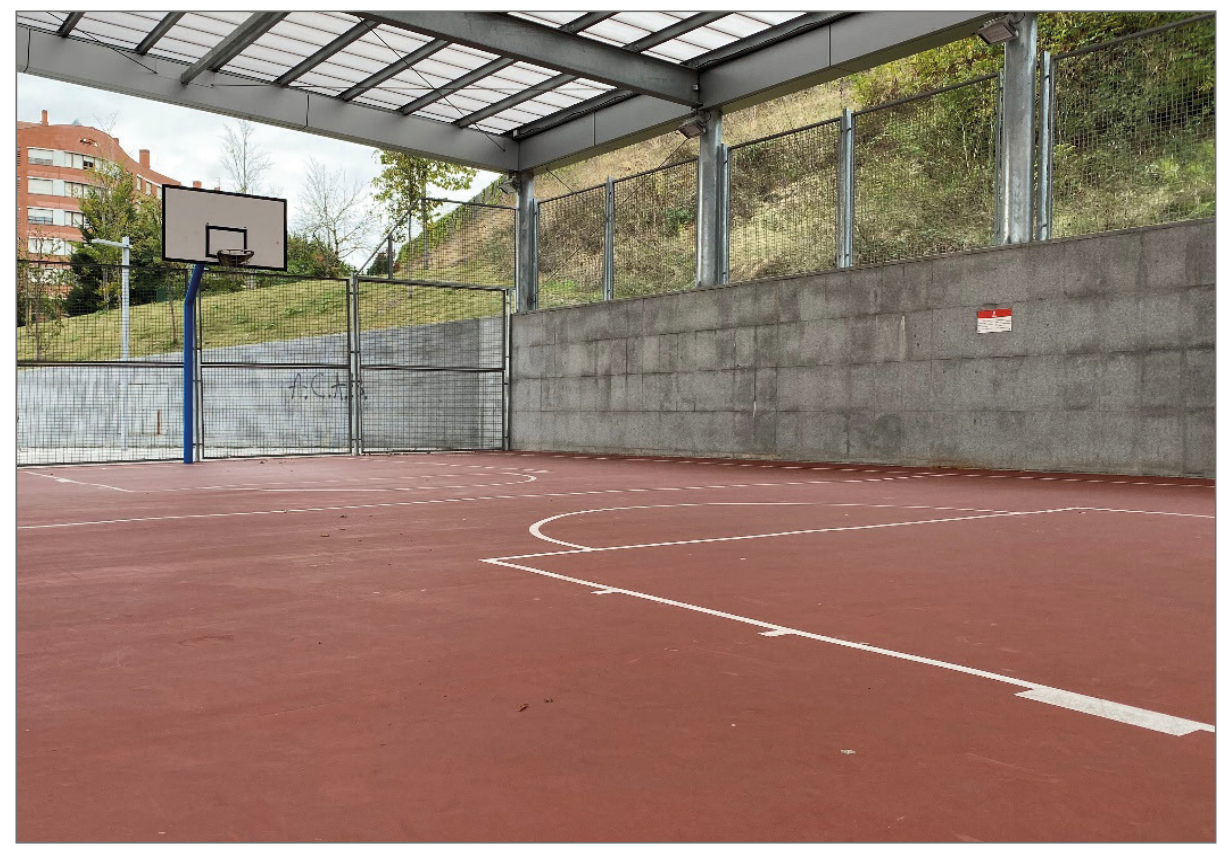

Cancha de Baloncesto situada en la zona de Basurto, Bilbao.

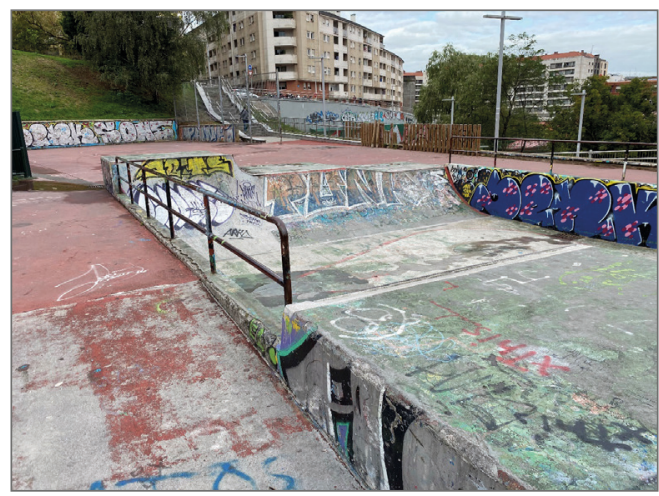

Pistas de patinaje en el parque de Eskurze, Bilbao.

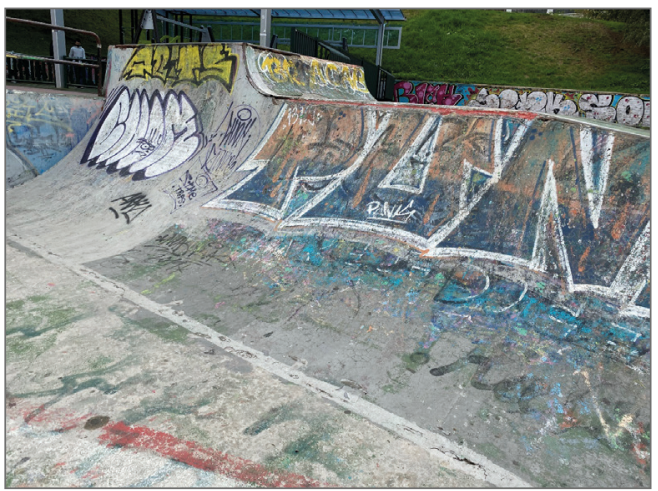



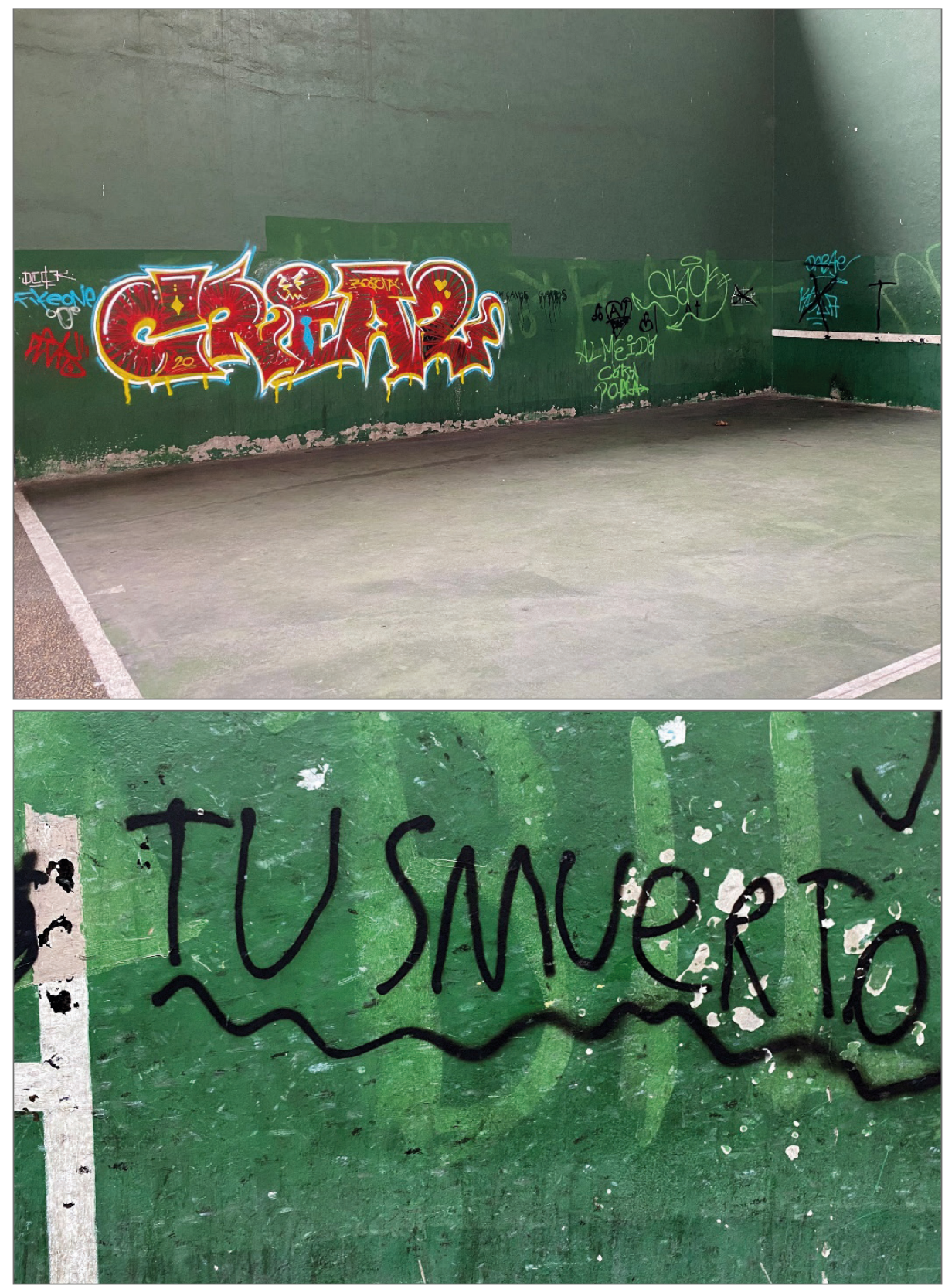

Frontón situado en el barrio de Rekalde, Bilbao. 
Es algo muy común comprobar cómo en los parques deportivos de las ciudades la extensión del juego se despliega más allá de sus límites prefijados. Sus plataformas, mobiliarios, muros, escalinatas, etc. son escenario y cobijo de acciones ligadas a la expresión creativa asociadas generalmente a una cultura popular esencialmente juvenil. Al tratarse de lugares en los que se da un consenso tácito para su empleo fuera de los modos conductuales que rigen la vida ordinaria, estimula una amplia variedad de acciones enérgicas y creativas que incentivan o vehiculan el descubrimiento del mundo y sus contingencias. De este modo, generación tras generación se solapan pintadas en las paredes y suelos que alientan a aquellos que las estampan, se proponen modos de vida alternativos, se bebe alcohol clandestinamente en sus rincones, y se manifiestan posturas políticas. Pérez de Arce citando a Duvignaud, afirma al respecto:

Duvignaud lo vislumbraba en cambio capturado por el orden establecido y antagónico a aquellas manifestaciones dionisiacas, libertarias, caóticas y multitudinarias -las llamaba estallidos lúdicos- que trastocaban el orden de la autoridad. Duvignaud extendía el sentido del juego al desenfreno creativo y su celebración de lo superfluo que -como en el barroco, ese 'delirio', 'visión catastrófica', 'imploración inquieta'- resultaba en puro gasto, expresión libre y última del exceso. Polemizaba contra las reducciones formales de un purismo ya desgastado, y la reducciones vivenciales de una ciudad funcionalmente estandarizada. Lo barroco se erigía a sus ojos como contraparte de la represión puritana, de la cual el capitalismo -'fórmula execrable de la acumulación si gozo'- representaba una expresión tardía de gran consecuencia.

(Pérez de Arce 2014, 83)

\section{LO VITAL Y EL ESPACIO. EL CASO DEL FRONTÓN DEL BARRIO DE REKALDE, BILBAO.}

La gente puede dar un uso a los parques (y hacerlos prosperar), o bien retraerse de usarlos y condenarlos al rechazo y el fracaso. Los parques son lugares volubles. Acusan tendencias extremas de popularidad o impopularidad. Su comportamiento no es en absoluto simple. Pueden ser rasgos encantadores de un distrito urbano, así como bienes económicos para los contornos; pero éstos son 
por desgracia los menos. Pueden con el tiempo llegar a ser más queridos y apreciados, aunque desgraciadamente pocos dan pruebas de esta resistencia. Por cada Rittenhouse Square, Rockefeller Plaza o Washingnton Square o Boston Common, o por cada feliz equivalente de otras muchas ciudades, hay docenas de vacios y desvaídos espacios urbanos llamados parques, carcomidos por la decadencia, el poco uso y el nulo cariño.

(Jacobs [1961] 2011, 119)

Los ciudadanos y vecinos de Bilbao bien conocen la extrema y peculiar morfología del barrio de Rekalde. Situado en las faldas del popular monte Pagasarri, entre los edificios que se levantan en el núcleo vital de este distrito una mole de hormigón lo sobrevuela y 'raja', condicionando fuertemente las diferentes operaciones urbanísticas que han tenido lugar a lo largo de las décadas, cristalizando soluciones superficiales que no resuelven el problema original y que soslayan la lógica de las reiteradas y constantes quejas vecinales: el paso de la autopista A8.

Bajo esta vía de cuatro carriles, soportada por 16 pilares de grandes dimensiones clavados en el pavimento de la plaza y distribuidas a lo largo de aproximadamente 300 metros, los niños juegan en las zonas recreativas mientras jóvenes y mayores conversan sentados en los numerosos bancos protegidos, paradójicamente, del sol y la lluvia. La última mitad de este trayecto alberga dos frontones, un campo de futbito, dos canchas de baloncesto y dos mesas de pingpong. Uno de los frontones se abre hacia la calle principal, el otro, sin embargo, esta situado en la parte trasera, en una especie de punto ciego del barrio. Tan sólo una pared compartida por ambos (la pared izquierda) delimita en este caso el uso o no de los mismos, su degradación o no.

Durante varios meses del año 2018 uno de estos frontones, aquel que se oculta de los ojos de los vecinos en el trasiego cotidiano del barrio, deja de ser escenario de la práctica de los diferentes juegos de la pelota, siendo desbordada y reemplazada su función arquitectónica la cual ahora vendría determinada por la necesidad de encontrar un sitio resguardado por parte de algo más de una veintena de personas sin hogar para hacer allí su vida. El frontón abandona su carácter de plataforma para el deporte y se torna en refugio forzado. La alteración aquí realizada provoca el deslizamiento de toda una variedad de gestos que tienen que ver con la esencia de lo político; solidaridad, disconformidad, comprensión, debate, búsqueda de soluciones. 
La respuesta vecinal ante esta nueva deriva en el uso del frontón es de asombro ya que, a pesar de que siempre ha sido lugar de pernoctación de aquellos que viven en la calle, lo que en esta ocasión lo convierte en extraordinario es el carácter de perdurabilidad y el número de personas, al tratarse del levantamiento de un campamento estable y duradero.

En un pleno del ayuntamiento del mes de junio (2018) se aprobó el cerramiento perimetral del frontón y el desalojo del mismo, en lo que se mostró como una solución deficitaria ya que al parecer, y según la información de prensa recopilada para este artículo, parte de esas personas continuaron en la calle buscando refugio nuevamente en otros frontones de Bilbao. La verja efectivamente se levantó dos semanas después, mide 28 metros de largo y 2,5 metros de alto y permanece cerrada durante la noche. Esta orden consistorial para la ejecución de un drástico cambio en el diseño del equipamiento y su espacio sería por el momento una medida intermedia ya que en enero de 2020 cristalizaría la solución urbana definitiva: la instalación de una "ludoteca multiusos al aire libre" con juegos interactivos, zonas de lectura y zonas para el desarrollo de talleres que pasan a ocupar los 300 metros cuadrados del antiguo frontón.

Asistimos ante una experiencia urbana fracasada en un desenlace formal que adopta un lenguaje contemporáneo fundamentado en significantes que organizan nuestra época actual, como la 'interactividad', 'conectividad', 'multiuso' 'software', 'app', 'creatividad' lo 'audiovisual', ideas todas ellas que sustentan el espíritu de este proyecto. Se abandona la interacción cuerpo-muro y lo que espacialmente se configura a través de ella, para pasar a establecerse un tipo de relación con la experiencia lúdica sometida a una especie de curriculm escolar, con la adopción de objetivos pedagógicos propios del contexto académico. Desaparece de este modo toda posibilidad de juego expansivo y no reglado, quedando marginada la exploración y la vivencia del espacio de forma autónoma, sin la mediación institucional que, como es en este caso, dirige y obstruye el acercamiento al conocimiento que se reconoce en la experimentación lúdica. Los niños exploran el espacio y su ambiente bajo la tendencia a actuar sobre el mismo, dirigen toda su energía a confrontar los límites que determinan un lugar. De esta manera, la espontaneidad y el movimiento son estrategias que el niño emplea para el conocimiento real del mundo y sus reglas (físicas, sociales y afectivas). Sin embargo, una zona de recreo diseñada para su contemplación bajo parámetros adultos de confortabilidad, agrado, limpieza, etc. sesgan de manera crítica el juego productivo y significativo ya que es el ambiente el que impone una forma pasiva y estática de exploración lúdica, 
reparando únicamente en lo mental. Lo que antes era calle ahora se ha transformado en la extensión de un aula del colegio al aire libre, supervisada por monitores y trabajadores del ámbito educativo y social, manteniendo con ello espacios artificiales y despojando a los menores del contacto con la realidad de su comunidad y sus vecinos que conforman el paisaje que necesariamente involucrará la conformación de su identidad aun en desarrollo.

En la vida real, los niños solo pueden aprender de la vida en común de los adultos en las aceras de la ciudad (si es que lo aprenden) el principio más fundamental de una buena vida urbana: todo el mundo a de aceptar un canon de responsabilidad pública mínima y recíproca, aun en el caso de que nada en principio les una. Es una lección que nunca se aprende con decirla. Se aprende de la experiencia, al comprobar que otras personas, con las cuales no nos une un particular vínculo, amistad o responsabilidad formal, aceptan y practican contigo un mínimo de responsabilidad pública.

(Jacobs [1961] 2011, 111-2)

En lo que concierne a la experiencia acontecida en el barrio de Rekalde, el desarrollo y desenlace de la línea de eventos suscitados alrededor de una problemática social profunda (que tiene que ver con la pobreza, la migración, la falta de recursos asistenciales, la relación con el paisaje, etc.), fuertemente condicionada aquí por su contextualización espacial, el frontón, evidencia una vez más la visión que desde las instituciones a menudo se tiene del papel del arte en la comunidad. Concretamente el empleo del arte como comodín legitimador de operaciones impulsadas para la gestión de conflictos sociales, especialmente cuando se trata de aludir a su carácter regenerador. En esta ocasión un tosco mobiliario de diseño ocupa el centro, cubierto doblemente el parque por la mole de hormigón y una nueva carpa. El verde característico del frontón ha desaparecido del todo y en su lugar se han pintado unos murales en los que predomina los tonos blancos, suaves y alegres. Al tiempo que el programa del proyecto de la nueva ludoteca se esfuerza por acentuar la práctica artística como una de sus actividades fundamentales junto con el fomento de la creatividad en los usuarios.

Puede entenderse, por tanto, que la experiencia aquí tratada ilustra la problemática entre el acometimiento de actuaciones que remiten claramente a su función y aquellas acciones que se mueven en la superficie formal y que atienden al carácter ornamental. En este caso, un espacio degradado responde, como se ha señalado anteriormente, a múltiples casuísticas de profunda penetración estructural en el lugar. Así, el hecho de 'incrustar' un proyecto urbanís- 
tico sin atender a las características del espacio en el que quiere intervenirse puede abocarle al fracaso. Realmente cabe pensar que no se dará solución a este conflicto si se deja de atender las condiciones estructurales que malogran reiteradamente este frontón trasero, esto es: el edificio de infraviviendas que ocupa uno de sus laterales, la penumbra que la cercanía de la autovía genera, el parking de coches que se sitúa al frente y la polución ambiental y sonora que provoca el parque rodado que le sobrevuela incesantemente.

Nos reiteramos, desde el conocimiento que nos otorga la experiencia propia del saber estético, en la necesidad de operar siempre estructuralmente en pos de un levantamiento real y trascendente.

En los casos en que se ha satisfecho totalmente el fin funcional, no queda cosa alguna por ornamentar.

(Moholy-Nagy [1929] 1997, 48)
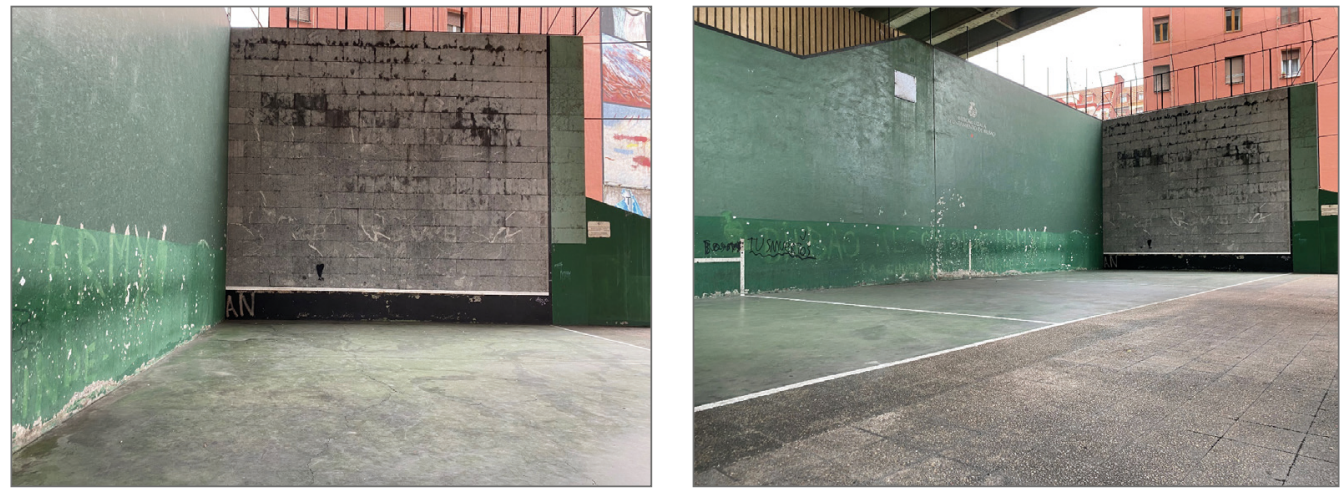

Frontón situado en el barrio de Rekalde, Bilbao. Imagenes superiores: frontón que se abre a una de las arterias principales, la calle Gordoniz. Imagen derecha: transformación del frontón contiguo y su cerramiento a través de valla metálica.

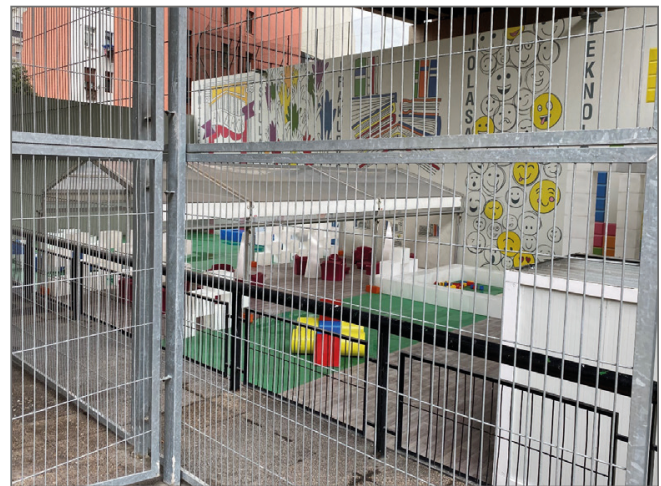



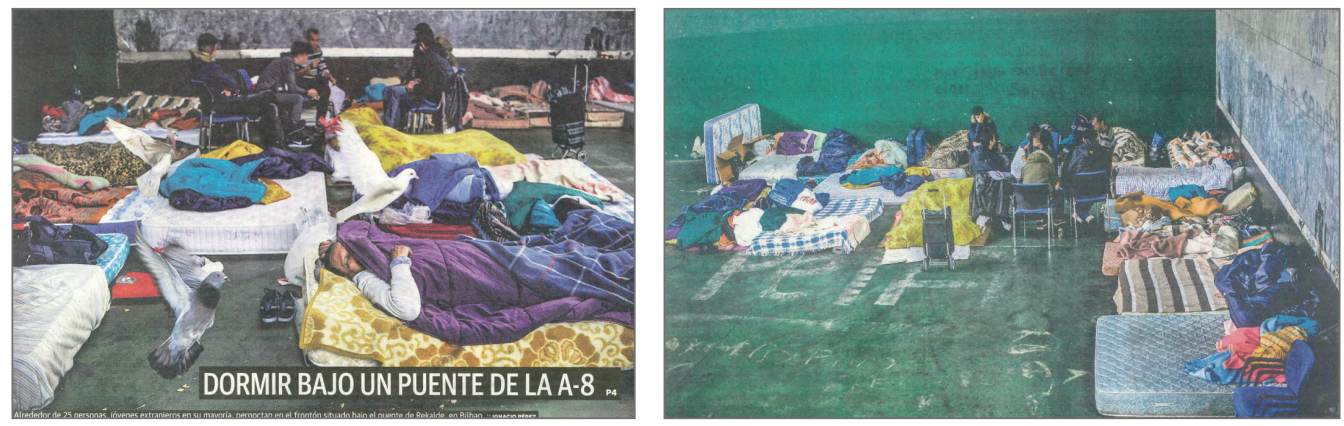

Imágenes publicadas en el periódico El correo. Fechas de publicación: 05-01-2018 (imagen izquierda) y 19-07-2018 (imagen derecha). Material documental obtenido en el archivo de la Biblioteca Foral de Bizkaia.
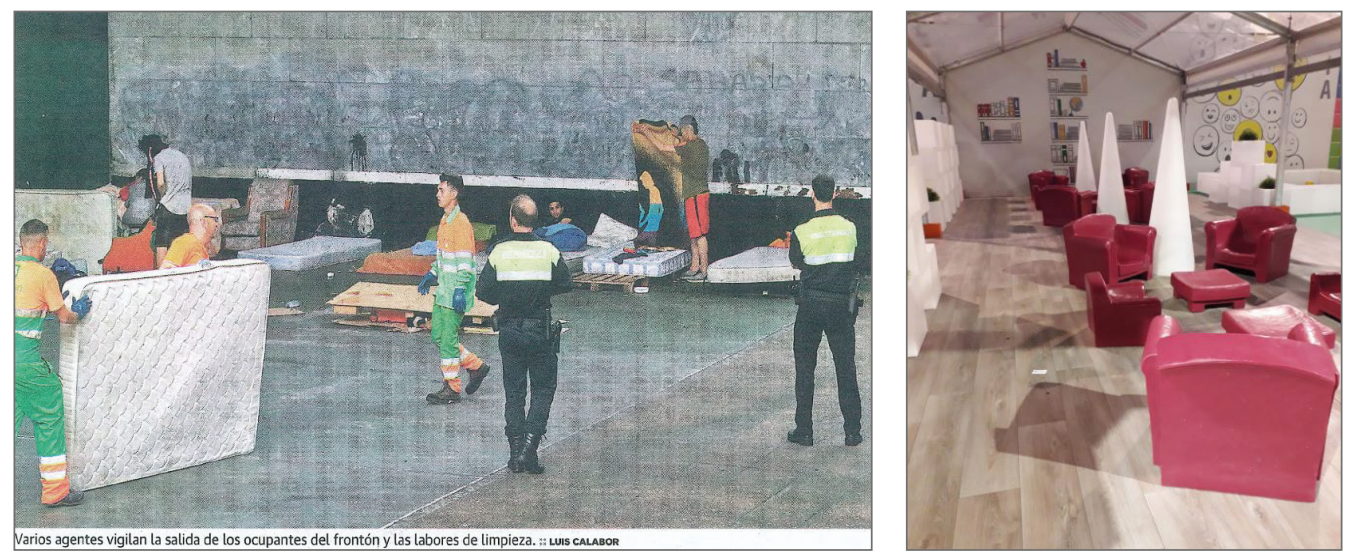

Imágenes publicadas en el diario Bilbao. Fechas de publicación: 20-07-2018 (imagen izquierda) y 1-04-2020 (imagen derecha). Material documental obtenido en el archivo de la Biblioteca Foral de Bizkaia.

\section{Referencias bibliográficas}

Hernández Martínez, Olatz. 2018. “La policía desaloja a los 30 ‘sin techo’ del frontón de Rekalde". El Correo, 20 jul. https://www.elcorreo.com/bizkaia/desalojan-sintecho-dormian-20180719111820-nt.html

Ibarrola, Martín. 2018. "25 camas bajo el puente de la autopista de Rekalde”. El Correo, 5 ene. https://www.elcorreo.com/bizkaia/camas-bajo-puente-20180106195046-nt.html

Jacobs, Jane. (1961) 2011. Muerte y vida de las grandes ciudades. Presentado por Zaida Muxí, Blanca G. Valdivia \& Manuel Delgado; traducido por Angel Abad \& Ana Useros. Madrid: Capitán Swing

Kavanaugh, Gerry. 2017. Race, politics and basketball: A cultural education of everyday life. Rotterdam: Sense 
Larsen, Lars Bang. 2014. "Círculos dibujados en el agua: el juego en tonalidad mayor". En Playgrounds: Reinventar la plaza, Museo Nacional Centro de Arte Reina Sofía, 30 abril-22 de septiembre de 2014, comisarios, Manuel Borja-Villel, Tamara Díaz Bringas \& Teresa Velázquez, 13-21. Madrid: MNCARS

Lecea, Ana. 2020. "Rekalde recupera el antiguo frontón como espacio de actividades del barrio". Bilbao, abril

Lorenz, Konrad. 1986. Fundamentos de la etología: Estudio comparado de las conductas. Traducción de Roberto Bein. Barcelona: Paidós

Martinez Zarracina, Pablo. 2018. "Cerramientos: Salen los inmigrantes y se cierran las canchas de Atxuri”. El Correo, 25 jul. https://www.elcorreo.com/bizkaia/cerramientos-20180725213511-nt.html

Moholy-Nagy, László. 1997. La nueva visión: y Reseña de un artista; [Principios básicos del Bauhaus]. Versión castellana, Brenda L. Kenny. Buenos Aires: Infinito

Oteiza, Jorge. (1963) 2009. Quousque tandem...! Ensayo de interpretación estética del alma vasca. Pamplona: Pamiela

Pérez de Arce, Rodrigo. 2014. "Calle y playground: La domesticación del juego en el proyecto moderno" En Playgrounds: Reinventar la plaza, Museo Nacional Centro de Arte Reina Sofía, 30 abril-22 de septiembre de 2014, comisarios, Manuel Borja-Villel, Tamara Díaz Bringas \& Teresa Velázquez. Madrid: MNCARS

Notas

${ }^{1}$ Extracto del libro Race, politics and basketball: A cultural education of everyday life, escrito por Gerry Kavanaugh, traducción realizada por el autor.

${ }^{2}$ Respecto a la estrecha relación entre la función del juego y la experiencia artística y su desarrollo el etólogo Konrad Lorenz hace la siguiente reflexión: "El juego libre de los factores que no tiende a ningún objetivo, que no se atiene a ninguna meta fijada por una teleología cósmica, el juego en que nada está predeterminado salvo las reglas de juego (...) seguramente sea la condición previa para todo acontecer creador en el verdadero sentido de la palabra, en el cual la cultura humana no constituye una excepción. La investigación del hombre, impulsada por su insaciable sed de conocimientos, es uno de estos aconteceres creadores y no resulta nada sorprendente que pueda desplegar su rendimiento pleno sólo cuando, despojada de todo objetivo predeterminado, se convierte en juego (...) La investigación humana se sitúa en la difuminada frontera entre la conducta de curiosidad y el juego; el arte humano pertenece indudablemente a la esfera del juego" (1986, 294-5).

${ }^{3}$ Se trata de unos de los movimientos fundamentales en la práctica del skateboarding. Se puede describir como un salto sobre el suelo y es la base para la realización de numerosos trucos.

(Artículo recibido: 04-10-20; aceptado: 27-11-20) 